\section{Recirculating loop trans- mission experiment over 57.6-km photonic crystal fiber}

\author{
Beáta Zsigri \\ Christophe Peucheret \\ Technical University of Denmark \\ Research Center COM \\ Building 345V \\ DK-2800 Kgs. Lyngby \\ Denmark \\ E-mail: bz@com.dtu.dk
}

\author{
Martin Dybendal Nielsen \\ Crystal Fibre A/S \\ Blokken 84 \\ DK-3460 Birkerød \\ Denmark \\ Palle Jeppesen \\ Technical University of Denmark \\ Research Center COM \\ Building 345V \\ DK-2800 Kgs. Lyngby \\ Denmark
}

\begin{abstract}
We demonstrate a 57.6-km-long linear photonic crystal fiber (PCF) transmission experiment using a recirculating loop with a 19.2-km PCF spool. A 10-Gbit/s nonreturn-to-zero signal was transmitted over PCF transmission fiber without dispersion compensation. () 2005 Society of PhotoOptical Instrumentation Engineers.

[DOI: 10.1117/1.1938977]
\end{abstract}

Subject terms: optical communications; fiber applications; transmission.

Paper 050273 L received Apr. 8, 2005; accepted for publication Apr. 26, 2005; appeared online Apr. 29, 2005; published online Jul. 22, 2005.

Photonic crystal fibers (PCFs) are very attractive for optical communication as they possess radically new features that cannot be achieved by their solid core-cladding fiber alternatives. ${ }^{1}$ A large variety of PCF types can be produced with pure silica core, potentially offering low loss, large effective area, and therefore reduced fiber nonlinearity. Single-mode PCFs have been fabricated with effective areas as large as $600 \mu \mathrm{m}^{2}$ (Ref. 2) and the endlessly single mode property has been shown to open up the possibility of building communication systems with over $160-\mathrm{THz}$ bandwidth. ${ }^{3}$ PCFs have also been proved to be applicable to distributed Raman amplified systems ${ }^{4}$ and short returnto-zero pulse propagation over a dispersion managed link. ${ }^{5}$ Recent improvement in production technologies has resulted in significantly reduced fiber loss and longer fibers. ${ }^{5,6}$ This has inspired intense research on using PCFs as transmission fibers. ${ }^{3-5,7-10}$ However, the transmission distances for linear, nondispersion managed systems reported until now have been limited to $12.7 \mathrm{~km} .{ }^{4}$ In this

0091-3286/2005/\$22.00 @ 2005 SPIE article, we demonstrate for the first time, to our knowledge, a recirculating loop experiment including $19.2 \mathrm{~km}$ of transmission PCF, thus extending the total length of transmission over PCF to $57.6 \mathrm{~km}$.

Two spools of endlessly single-mode PCF with lengths of 8.8 and $10.4 \mathrm{~km}$ have been used in the transmission experiment. The fibers are made from pure silica. The cladding has a closed packed structure with hole-to-hole spacing $(\Lambda)$ of 7.5 and $6.3 \mu \mathrm{m}$ for the 8.8 - and $10.4-\mathrm{km}$ spools, respectively, and the diameter of the air holes relative to $\Lambda$ is 0.49 in both cases. Both fibers have a cladding diameter of $125 \mu \mathrm{m}$ and a coated diameter of $240 \mu \mathrm{m}$. The two spools were spliced together from five pieces of fiber with an average length of $4 \mathrm{~km}$, the longest piece being $6.4 \mathrm{~km}$ long. All fiber pieces have less than $1 \mathrm{~dB} / \mathrm{km}$ loss at 1550 $\mathrm{nm}$. The 10.4-km fiber has a mode field diameter of $7.5 \mu \mathrm{m}$ and a dispersion of $34.5 \mathrm{ps} / \mathrm{nm} / \mathrm{km}$ at $1550 \mathrm{~nm}$, while the mode field diameter and the dispersion of the $8.8-\mathrm{km}$ fiber are $9 \mu \mathrm{m}$ and $31.5 \mathrm{ps} / \mathrm{nm} / \mathrm{km}$ at $1550 \mathrm{~nm}$, respectively. These mode field diameter values translate into effective areas of 44 and $64 \mu \mathrm{m}^{2}$ for the $10.4-$ and $8.8-\mathrm{km}$ spools, respectively.

The setup used for the transmission experiment is shown in Fig. 1. The transmitter consisted of a CW laser source emitting at $1550 \mathrm{~nm}$ followed by a polarization controller and a chirp-free $\mathrm{LiNbO}_{3}$ Mach-Zehnder modulator (MZM). A pseudo random bit sequence (PRBS) with a length of $2^{31}-1$ was applied to the MZM to generate a $10 \mathrm{Gbit} / \mathrm{s}$ non-return-to-zero (NRZ) modulated signal. An erbiumdoped fiber amplifier (EDFA) boosted the signal before it was coupled into the loop switch via a variable attenuator and a polarization controller. The loop switch consisted of two cascaded acousto-optic switches (AOS) to control the filling time of the loop and an additional AOS to control the number of round trips the signal travels before detection. In the loop, the signal was first boosted by an EDFA before being launched in the transmission line. The transmission line consisted of the two spools of PCF with lengths of 10.4 and $8.8 \mathrm{~km}$. The average input power into the PCF was $15.8 \mathrm{dBm}$. At the output of the second PCF, an EDFA was used to compensate for the span loss before the signal was

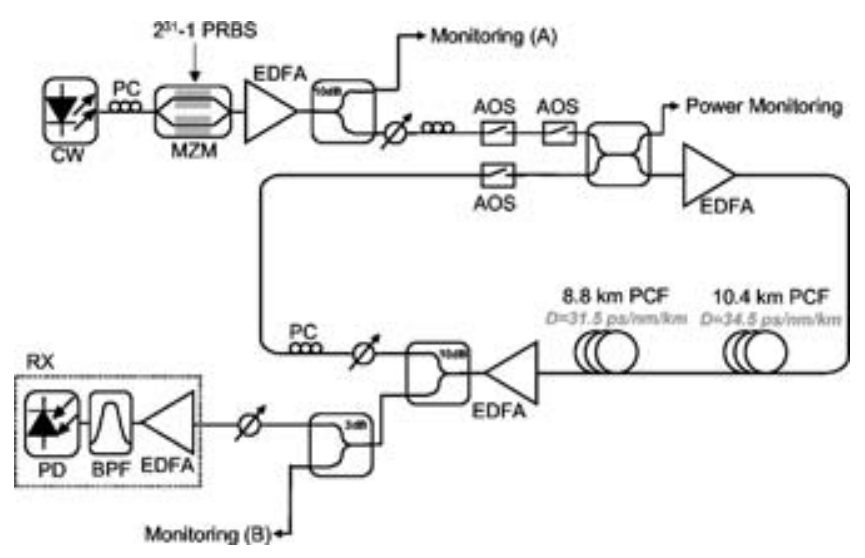

Fig. 1 Experimental setup. CW: continuous-wave laser; PC: polarization controller; MZM: Mach-Zehnder modulator; EDFA: erbiumdoped fiber amplifier; AOS: acousto-optic switch; PCF: photonic crystal fiber; BPF: optical bandpass filter; PD: photodiode. 
reinjected into the loop switch. A $10-\mathrm{dB}$ power splitter enabled the signal to be coupled into an optically preamplified receiver.

The back-to-back eye diagram (recorded at point $\mathrm{A}$ in Fig. 1) corresponding to an extinction ratio of $14.8 \mathrm{~dB}$ is shown in Fig. 2(a). The eye diagrams after 19.2-, 38.4-, and 57.6-km transmission over PCF (recorded at point B in Fig. 1) are shown in Figs. 2(b), 2(c), and 2(d), respectively. All eye diagrams were monitored in a $26-\mathrm{GHz}$ bandwidth. The eye-diagram distortion is mainly attributed to dispersion. Due to the high fiber input power, some pulse reshaping due to self-phase modulation (SPM) in the anomalous dispersion regime can also be observed in the eyes.

The bit error rate curves measured in the back-to-back case and after transmission are plotted in Fig. 3. A back-toback sensitivity of $-33.9 \mathrm{dBm}$ has been obtained. The power penalty measured after 19.2, 38.4, and $57.6 \mathrm{~km}$ (corresponding to 636,1272 , and $1908 \mathrm{ps} / \mathrm{nm}$ accumulated dispersion, respectively) was $0.1,0.7$, and $3.4 \mathrm{~dB}$, respectively. As a comparison, in the case of linear propagation, $1-\mathrm{dB}$ power penalty is expected in a standard single-mode fiber-based transmission line for around 1000-ps/nm accumulated dispersion. ${ }^{11}$ The measured lower power penalty values confirm the interaction of SPM with anomalous dispersion.

We have demonstrated what we believe is the longest nondispersion managed transmission experiment using PCF as a transmission fiber to date. A 10-Gbit/s NRZ signal was transmitted in a recirculating loop consisting of a $19.2-\mathrm{km}$ transmission PCF. The signal was successfully transmitted over $57.6 \mathrm{~km}$ of PCF with only $3.4-\mathrm{dB}$ power penalty. The transmission distance was mostly limited by dispersion.

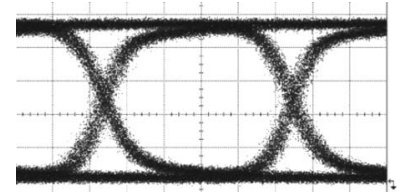

(a)

(c)

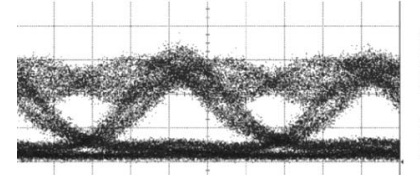

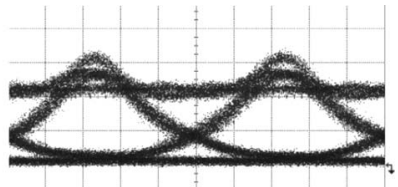

(b)

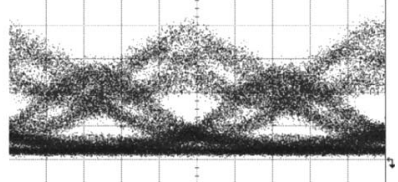

(d)
Fig. 2 Eye diagrams measured (a) in the back-to-back case and after (b) $19.2-\mathrm{km}$, (c) $38.4-\mathrm{km}$, and (d) $57.6-\mathrm{km}$ transmission over PCF.

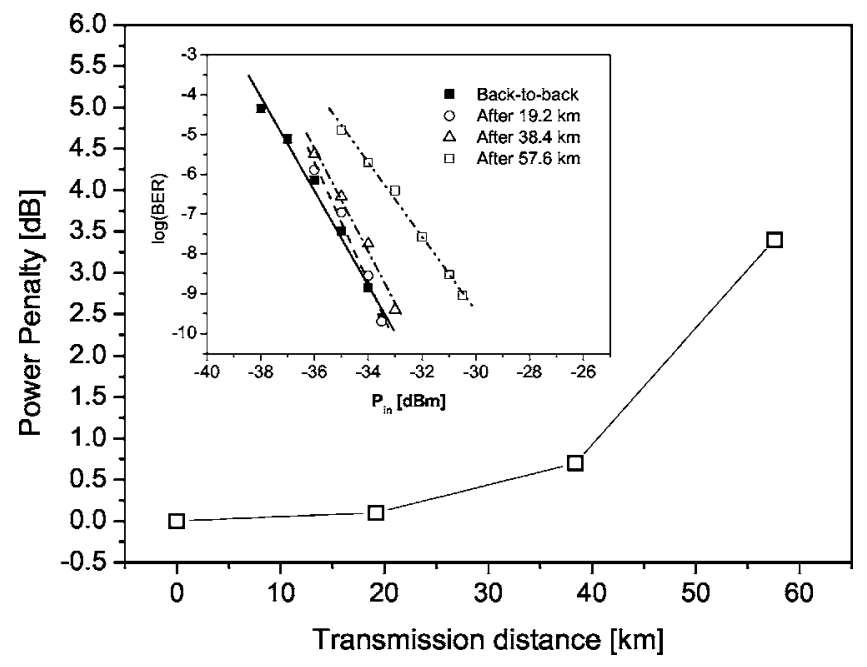

Fig. 3 Power penalty as a function of transmission distance. The inset shows the bit error ratio curves measured in the back-to-back case and after 19.2-, 38.4-, and 57.6-km transmission over PCF.

\section{References}

1. P. Russell, "Photonic crystal fibers," Science 299, 358-362 (2003).

2. M. D. Nielsen, J. R. Folkenberg, and N. A. Mortensen, "Singlemode photonic crystal fibre with effective area of $600 \mu \mathrm{m}^{2}$ and low bending loss," Electron. Lett. 39(25), 1802-1803 (2003).

3. K. Nakajima, J. Zhou, K. Tajima, K. Kurokawa, C. Fukai, and I. Sanakawa, "Ultra wide band $190 \mathrm{Gbit} / \mathrm{s}$ WDM transmission over a long length and low loss PCF," OFC'04, PDP23 (2004).

4. C. Fukai, K. Nakajima, J. Zhou, K. Tajima, K. Kurokawa, and I. Sankawa, "Distributed Raman amplification based DWDM transmission in a low loss photonic crystal fibre," ECOC'04, Wel.3.6 (2004).

5. K. Kurokawa, K. Tajima, J. Zhou, K. Nakajima, T. Matsui, and I. Sankawa, "Penalty-free dispersion-managed soliton transmission over $100 \mathrm{~km}$ low loss PCF," OFC'05, PDP21 (2005).

6. K. Tajima, J. Zhou, K. Kurokawa, and K. Nakajima, "Low water peak photonic crystal fibres," ECOC'03, post-deadline paper Th4.1.6 (2003).

7. K. Tajima, J. Zhou, K. Nakajima, and K. Sato "Ultra low loss and long length photonic crystal fibre," OFC'03, PD1 (2003)

8. K. Suzuki, H. Kubota, S. Kawanishi, M. Tanaka, and M. Fujita, "High-speed bi-directional polarization division multiplexed optical transmission in ultra low-loss $(1.3 \mathrm{~dB} / \mathrm{km})$ polarisation-maintaining photonic crystal fibre," Electron. Lett. 37(23), 1399-1401 (2001).

9. B. Zsigri, C. Peucheret, M. D. Nielsen, and P. Jeppesen, "Transmission over $5.6 \mathrm{~km}$ large effective area and low-loss $(1.7 \mathrm{~dB} / \mathrm{km})$ photonic crystal fibre," Electron. Lett. 39(10), 796-798 (2003).

10. C. Peucheret, B. Zsigri, P. A. Andersen, K. S. Berg, A. Tersigni, P. Jeppesen, K. P. Hansen, and M. D. Nielsen, "40 Gbit/s transmission over photonic crystal fibre using mid-span spectral inversion in highly nonlinear photonic crystal fibre," Electron. Lett. 39(12), 919921 (2003).

11. A. E. Willner and B. Hoanca, "Fixed and tunable management of fiber chromatic dispersion," Optical Fiber Telecommunications IV B, I. P. Kaminow and T. Li, Eds., pp. 642-724, Academic Press, San Diego (2002). 